\title{
An Unusual Clinical Appearance of Lymphangioma in the Cheek of a 52-Year-Old Female - A Rare Case Report
}

\author{
Nivedha Senthilnathan' ${ }^{1}$, Mohan Narayanan², Kumar Appusamy33, Karthik Rajaram Mohan", \\ Sabitha Gokul Raj ${ }^{5}$, Ravikumar Thangavel ${ }^{6}$ \\ 1,2,3,4,5,6 Department of Oral Medicine and Radiology, Vinayaka Missions Sankarachariyar Dental College, \\ Vinayaka Missions Research Foundation, Salem, Tamilnadu, India.
}

\section{INTRODUCTION}

Lymphangioma is a rare developmental hamartomatous malformation of the lymphatic vessels. It usually occurs in the dorsum of the tongue resulting in macroglossia that can interfere with speech and mastication. About $10 \%$ of lymphangiomas can occur in the buccal mucosa resulting in multiple discrete vesicle like structures resembling frogs-egg or pebbly surface or Tapioca pudding like appearance containing clear proteinaceous rich fluid. They also can appear reddish or reddish - purple coloured pebbly surface and are completely asymptomatic. In due course can result in painless, asymptomatic soft tissue swelling on the face resulting in facial disfigurement. Such a rare occurrence of lymphangioma reported in the cheek of a 52-year-old female and treated by ultrasonographic guided Bleomycin sclerotherapy is discussed here.

A lymphangioma is a misnomer as it is not a tumour of lymphatic vessels. It is a developmental hamartomatous malformation of the lymphatic vessels that usually clinically becomes more apparent only after second year of age. Clinically they appear as painless soft swellings of the face resulting in facial asymmetry. Patients affected by lymphangioma usually report to the physician or a dentist and complain only of cosmetic defect. ${ }^{1}$

\section{PRESENTATION OF CASE}

A 52 - year - old female reported to our department with a chief complaint of swelling on the left side of her cheek for the past one year. Patient visited a private dental clinic for swelling in the same left cheek region about 2 months back, for which she was prescribed analgesic and antibiotic medication, but the swelling remained same and she came to the outpatient department of Oral medicine and Radiology for treatment. There was no pain, epistaxis, nasal stuffiness, or paraesthesia associated with the swelling.

Patient was not an asthmatic, hypertensive or diabetic. Her family history was non - contributory. General examination revealed her vitals as stable. No regional lymphadenopathy. Extra oral examination showed facial asymmetry due to the presence of swelling on the left side of the cheek. (Figure 1a).
Corresponding Author:

Dr. Nivedha $S$.

5/1234, Ponnagar Jagir

Ammapalayam, Salem - 636302,

Tamilnadu, India.,

E-mail: koteeswari15595@gmail.com

DOI: $10.14260 /$ jemds/2021/436

How to Cite This Article:

Senthilnathan N, Narayanan M, Appusamy $K$, et al. An unusual clinical appearance of lymphangioma in the cheek in a 52-year-old female - a rare case report. J Evolution Med Dent Sci 2021;10(28):2134-2138, DOI: $10.14260 /$ jemds/2021/436

Submission 27-02-2021,

Peer Review 10-05-2021,

Acceptance 18-05-2021,

Published 12-07-2021.

Copyright (C) 2021 Nivedha Senthilnathan et al. This is an open access article distributed under Creative Commons Attribution License [Attribution 4.0 International (CC BY 4.0)] 


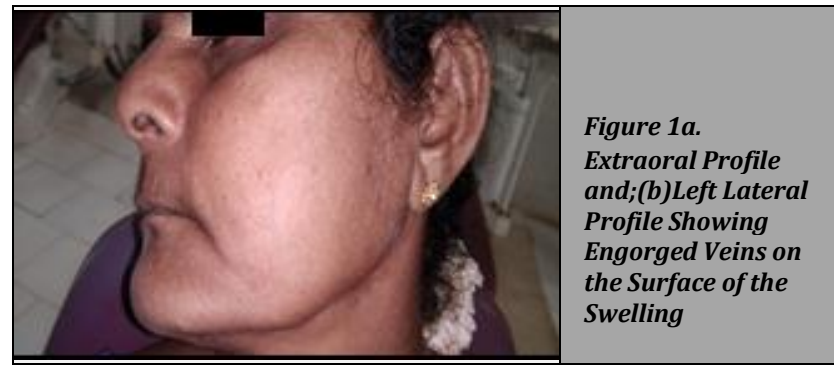

On palpation all the inspection findings regarding the site, size, shape, surface, extent of the swelling was confirmed. There was no tenderness on palpation, and was soft in consistency, fluctuant, compressible, and not reducible. There was absence of any palpable fluid thrill or warmth on the surface of the skin associated with the swelling.

The patient was completely edentulous. Intraoral examination revealed an area of multiple violaceous discoloured pebbly surface measuring approximately $4 \times 3 \mathrm{~cm}$ seen on the left buccal mucosa. A straw-coloured fluid tinged with blood was seen during intraoral bidigital palpation of the left buccal mucosa. (Figure 2)

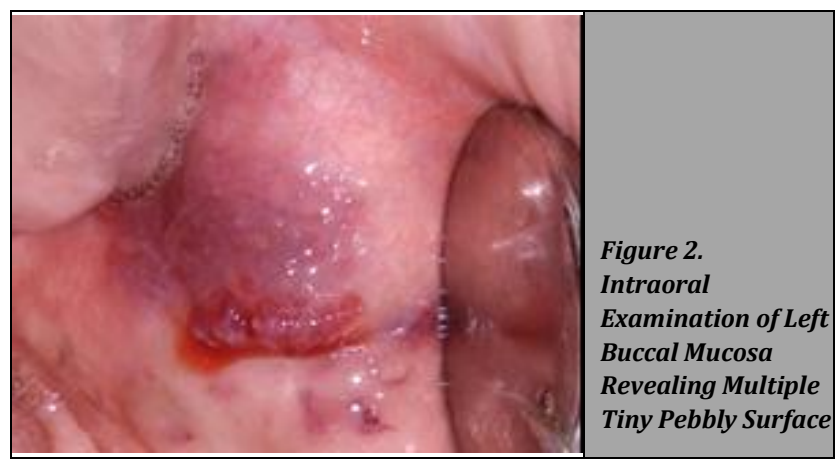

The axial section of Contrast enhanced computed tomography revealed a homogeneous expansile mass measuring $4.3 \times 2.8 \times 2.4 \mathrm{~cm}$ in relation to the left cheek region. There was no destruction or breach in the cortical plate in either the buccal or lingual cortical plate of the underlying maxillary alveolar bone. (Figure 3a).

The axial section revealed intact walls of maxillary sinus and no extension of expansile mass into the maxillary sinus or perforation of walls of the maxillary sinus. (Figure $3 \mathrm{~b}$ ). The sagittal section also confirmed the presence of a homogenous expansile mass measuring $4.3 \times 2.8 \times 2.4 \mathrm{~cm}$ in the left cheek region. (Figure 3c).

After scrubbing the skin of the left cheek with povidone iodine, ultrasonographic guided fine needle aspiration was done (Figure 4a) which revealed a $2 \mathrm{ml}$ straw coloured, honey - like viscous fluid mixed with blood. (Figure 4b.)

Correlating the chief complaint, history, clinical findings, radiographic findings, ultrasonographic guided fine needle aspiration, and a provisional diagnosis of benign soft tissue cyst involving the left cheek was made.

The differential diagnosis included the following Haemangioma, arteriovenous malformation, acinic cell carcinoma or lymphangioma due to their violaceous coloured appearance on the surface of left buccal mucosa.

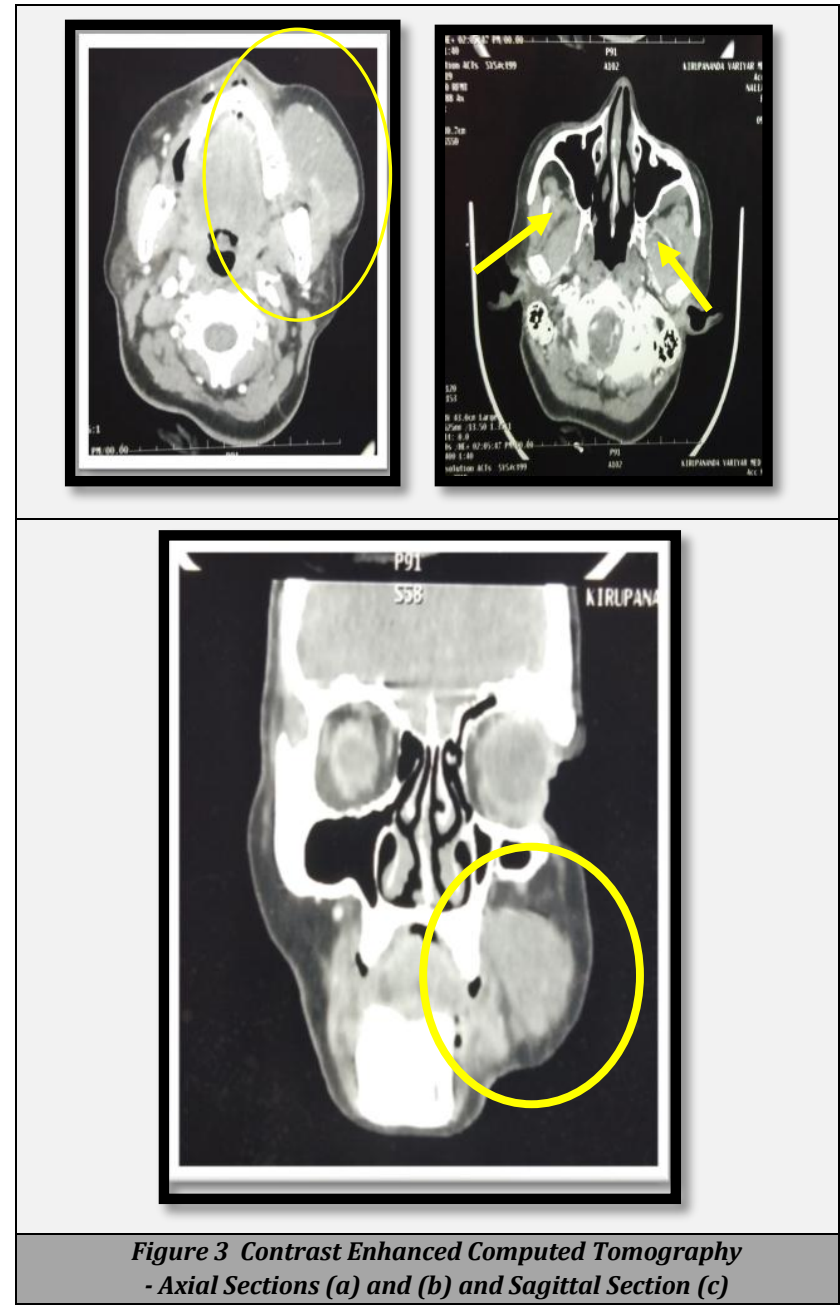

With the above clinical findings and radiological findings, a final diagnosis of lymphangioma involving the left cheek was made.

\section{DISCUSSION OF MANAGEMENT}

A first dose of 15 units of bleomycin powder was mixed with 2 $\mathrm{ml}$ of $0.1 \mathrm{~N}$ saline and was injected intralesionally under guided ultrasonography. (Figure $5 \mathrm{a}$ ) A second dose of same concentration of $2 \mathrm{ml}$ intralesional bleomycin sclerotherapy was performed under ultrasonographic guidance at 1 - week interval. (Figure 5b). Bleomycin is an antitumor glycopeptide antibiotic drug which is cell cycle specific for G2 phase binding to guanosine - cytosine - rich portions of DNA. The positive charge at the terminal amine of the drug interacts with negatively charged DNA by electrostatic attraction and the planar bithiazole moiety intercalates with DNA. The activated molecular oxygen at the axial site of the bleomycin BLM - Fe (II) complex reacts with DNA. Intercalation of the bithiazole rings produce highly reactive free radicals and Fe (III).

The free radicals produce DNA single-strand breaks at 3' 4' bonds in deoxyribose nitrogenous bases of DNA. This yields free base propenyls, which are highly cytotoxic to thymine. Only erythema was noted intraorally at the site of intralesional injection of first dose of bleomycin sclerotherapy. The injected area also appeared more reddish purple in colour and there was a consolidation of the pebbly surface areas on the left 
buccal mucosa during the second dose of intralesional injection of bleomycin, that was initiated after a week.
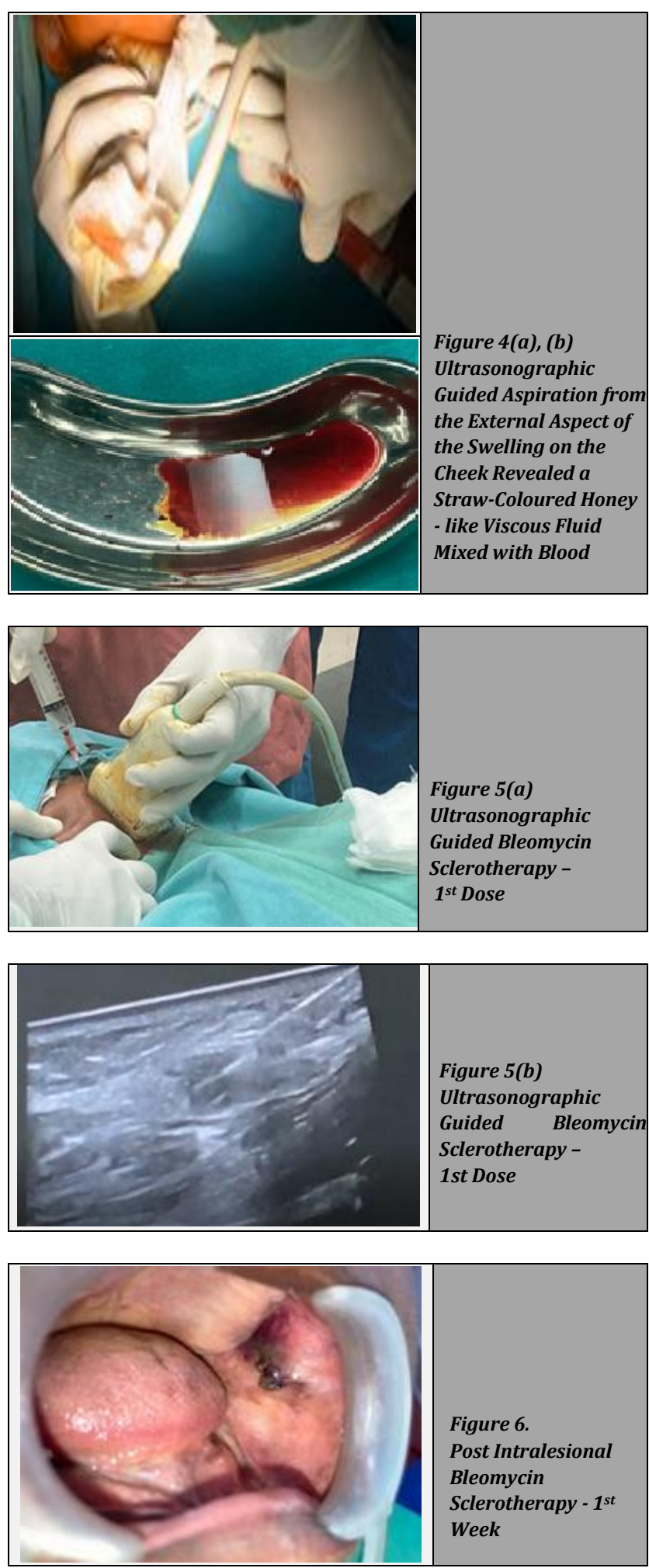

(Figure 6) No other subjective symptoms like vomiting, nausea, fever or respiratory distress due to pulmonary fibrosis were noted during bleomycin sclerotherapy. Patient showed reduction in the number and size of the macrocystic spaces on ultrasonographic imaging, showing resolution of the lesion. (Figure 7a) Satisfactory healing was appreciated at the intraoral intralesional injected site after a week of second dose of intralesional bleomycin sclerotherapy guided under ultrasonography. The pebbly surface disappeared on the affected left buccal mucosa. (Figure $7 \mathrm{~b}$ ) No recurrence of the swelling was noted after a three-month follow-up after the second dose of intralesional bleomycin sclerotherapy for which the patient responded well.

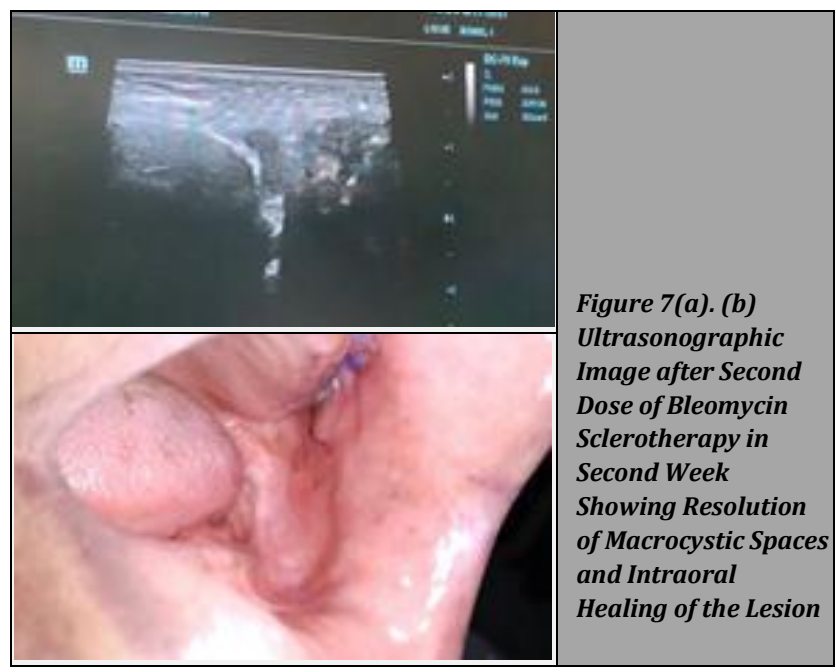

\section{DISCUSSION}

The term "Lymphangioma" is a misnomer, since it is considered to be a hamartomatous, benign, congenital malformation of lymphatic vessels that arise from sequestration of lymphatic tissue during the embryonic period of lymphatic vessel formation that does not normally communicate with the rest of the lymphatic system or as a consequence of inadequate lymphatic drainage by an external cause such as trauma or palpation leading to the destruction of lymphatic vessel and resulting in obstruction of local lymphatic drainage which causes swelling as a result of pooling of lymphatic fluid. In 1828 Redenbacher first described lymphangioma as "Ranula congenital". The first case report on a type of lymphangioma called cystic hygroma was given by Werner. The term Hygro - derived from Greek word means "Fluid", oma-means "Tumour". In 1872, Koester suggested that cystic hygromas were derived from lymphatic tissues. ${ }^{2}$ Clinically lymphangioma occurs before 2 years of age. The incidence of lymphangioma is only about 1 - 3 among 1000 new-borns. The International Society for the study on vascular anomalies in 2018 classified various types of lymphatic malformations and genes associated with it. ${ }^{3}$

A detailed literature search on lymphangioma made in Pubmed revealed 7,201 articles of which only 10 pubmed articles were related to cases of lymphangioma on the buccal mucosa. Further search on literature of occurrence of lymphangioma on the buccal mucosa revealed 3 articles using Cochrane library search engine. Hence a total of 15 case report studies revealed the occurrence of lymphangioma on the buccal mucosa. . $^{-19}$

The most common extraoral sites are the eyes, spleen, gastric mesentery, thorax, skin over the axilla and genital regions such as prostrate, scrotum in males and vulva in females. Intraorally, most common locations involve the anterior aspect of the dorsum of the tongue, Buccal mucosa, Hard palate, vermilion border of lip, tonsils, alveolar ridge, and floor of the mouth involving the submandibular region and Parotid region. Lymphangiomas affecting the tongue, appears 
as macroglossia, pebbly surface or frogs - egg resembling a cluster of translucent vesicles or Tapioca pudding surface. The International society for the study of vascular anomalies in 2018 proposed a new classification for lymphatic malformations at the General assembly, Amsterdam in Netherlands. $^{2}$ The morphological classification of lymphangiomas include macrocystic (size $>2 \mathrm{~cm}^{3}$ ), microcystic $\left(\right.$ size $<2 \mathrm{~cm}^{3}$ ) and mixed variants.

\section{Classification of Lymphangiomas}

Landing and Farber classified lymphangioma into three types, a] lymphangioma simplex (capillary lymphangioma), b] cavernous lymphangioma, and c] cystic lymphangioma (cystic hygroma)]. ${ }^{20}$ Recently, numerous relatively specific antibodies for lymphatic vessels have been identified such as podoplanin, lymphatic vessel endothelial HA-receptor-1, vascular endothelial growth factor receptor 3, Prox 1 and D2 - 40.4

The various treatment modalities for lymphangioma in the literature search revealed the usefulness of surgical excision by Nd: YAG or CO2 or Pulsed - dye - lamp lasers, Plasma knife surgery, cryotherapy, Bipolar radiofrequency - induced interstitial thermoablation, sclerotherapy with the use of Picibanil (OK - 432), a lyophilized incubated mixture of strain of streptococcus A - Streptococcus pyogenes with penicillin G Potassium, which has lost its streptolysin S - producing ability, alcoholic solution of zein (Ethibloc), a biodegradable thrombogenic solution consisting of a combination of zein (corn protein) as a thrombogenic agent, sodium amidotrizoate as a $\mathrm{x}$ - ray contrast material, and oleum papaveris as softener, tetradecyl sulphate, hypertonic saline, $25 \%$ dextrose, Polidocanol (hydroxypolyathoxydodecan), sodium morrhuate, tincture of iodine, boiling water, urethane, nitromine, Harashima $\mathrm{T}$ et al. advocated the use of pulsed $\mathrm{Nd}$ : YAG laser (d - lase 300, American Dental Laser, Detroit, MI) for the treatment of lymphangiomas. Exposure time was for 10 min each at an interval of 10 days, with the energy density of 1 W, 10 Hz. ${ }^{16}$

Plasma knife surgery, a new modality used in the surgical excision of superficially located lymphangioma in which there is very little thermal damage to the adjacent surrounding tissue as the probe tip remains cool at $70-80^{\circ} \mathrm{C}$ throughout the surgical excision procedure and also has an added advantage of no saline irrigation required during the procedure. Bipolar radiofrequency - induced interstitial thermoablation (BRIT) Radiofrequency ablation is more preferred for haemorrhagic lingual lymphangiomas involving the tongue, because of high tendency to bleeding and retropharyngeally located lymphangiomas that can lead to both dyspnoea and dysphagia. BRIT produces a vibration within the cells resulting in controlled temperature which increases within the affected tissue resulting in denaturation of proteins and enables the volume of the tissue to be clearly chosen.

Matharu et al. suggested Cryotherapy for treatment of lymphangiomas that involves thawing and destruction of the affected area by cryo - probe tips which use liquid nitrogen within the aesthetic zone but do not always provide complete resolution or success. ${ }^{21}$ Oxford $\mathrm{J}$ et al. recommended bleomycin for the treatment of lymphangiomas. ${ }^{22}$

In our case ultrasonographic guided bleomycin sclerotherapy was performed. Intralesional bleomycin acts by damaging the endothelial lining of the lymphangioma and also by inducing thrombosis and fibrosis around the vascular spaces of lymphangioma by diffusion of chemical into the cystic spaces. Sclerotherapy is limited to lymphangiomas containing microcystic spaces that can prevent diffusion of sclerosing agent from one lumen to another.

\section{CLINICAL SIGNIFICANCE}

Lymphangioma is a rare congenital anomaly of the lymphatic vessels that can cause facial disfigurement. The treatment of such lymphangioma is challenging and depends on the anatomical location, size of the lesion. The early diagnosis and intervention of oral lymphangioma is essential for the dentist and it also helps in reducing the functional disturbance of interference in mastication and speech, psychological disturbances caused by their cosmetic disfigurement as experienced by the patient.

\section{CONCLUSIONS}

Lymphangioma is rare in adults and it should be considered under differential diagnosis of soft tissue swelling on the buccal mucosa. Early diagnosis helps in providing better treatment options to the patients.

Financial or other competing interests: None.

Disclosure forms provided by the authors are available with the full text of this article at jemds.com.

Authors thank all teaching faculties of department of oral medicine and radiology.

\section{REFERENCES}

[1] De Carvalho FK, Pinheiro TN, Da Silva RAB, et al Lymphangioma of lower lip mimicking a mucocele in children. J Dent Child (Chic) 2015;82(2):116-9.

[2] McGill TJ, Mulliken JB. Vascular anomalies of the head and neck. Vol. 1. $2^{\text {nd }}$ edn. In: Cummings CW, Friedrickson JM, Harker LA, et al, eds. Otolaryngology-Head And Neck Surgery. St. Louis: Mosby 1993:333-46.

[3] International society for the study of vascular anomalies. ISSVA classification of Vascular Anomalies 2018. issva.org/classification. Accessed [17.01.21]

[4] Kolay SK, Parwani R, Wanjari S, et al. Oral lymphangiomas-clinical and histopathological relations: an immunohistochemically analyzed case series of varied clinical presentations. J Oral Maxillofac Pathol 2018;22(Suppl 1):S108-11.

[5] Tayefeh A, Asadollahi A, Saatloo MV. A rare case report of oral lymphangioma in buccal mucosa. Ann Clin Case Stud 2020;2(4):1035.

[6] Kurude AA, Phiske MM, Kolekar KK, et al. Lymphangiomas: rare presentations in oral cavity and scrotum in pediatric age group. Indian J Dermatol Venereol Leprol 2020;86(2):230. 
[7] Yalçin M, Laçin N. Lymphangioma in the buccal mucosa. J Craniofac Surg 2019;30(8):e696-7.

[8] Devi A, Narwal A, Yadav AB, et al. Classical cases of lymphangioma-as multiple vesicular eruptions. J Clin Diagn Res 2016;10(6):ZD22-3.

[9] Babu DB, Kumar BR, Boinepally $\mathrm{NH}$, et al. A case of intraoral lymphangioma circumscripta-a diagnostic dilemma. J Clin Diagn Res 2015;9(10):ZD11-3.

[10] Kaur M, Gombra V, Subramanyam R, et al. Lymphangioma of the buccal mucosa-a case report and review of literature. J Oral Med Oral Surg Oral Pathol Oral Radiol 2015;1(3):123-5.

[11] Pammar C, Kotrashetti VS, Nayak R, et al. Lymphangioma of the buccal mucosa: a case report with a literature review. J Orofac Sci 2015;7(2):129-31.

[12] Yoganna SS, Prasad RGR, Sekar B. Oral lymphangioma of the buccal mucosa a rare case report. J Pharm Bioallied Sci 2014;6(Suppl 1):S188-91.

[13] Bhayya H, Pavani D, Tejasvi MLA, et al. Oral lymphangioma: a rare case report. Contemp Clin Dent 2015;6(4):584-7.

[14] Dogan N, Durmaz CE, Sencimen M, et al. The treatment of recurrent lymphangioma in the oral buccal mucosa by cryosurgery: a case report. OHDMBSC 2010;9(1):7-10.
[15] Bozkaya S, Ugar D, Karaca I, et al. The treatment of lymphangioma in the buccal mucosa by radiofrequency ablation: a case report. Oral Surg Oral Med Oral Pathol Oral Radiol Endod 2006;102(5):e28-31.

[16] Harashima T, Hossain M, Walverde DA, et al. Treatment of lymphangioma with Nd: YAG laser irradiation: a case report. J Clin Laser Med Surg 2001;19(4):189-91.

[17] Brennan TD, Miller AS, Chen SY. Lymphangioma of the oral cavity: a clinicopathologic, immunohistochemical and electron-microscopic study. J Oral Maxillofac Surg 1997;55(9):932-5.

[18] Taşar F, Tümer C, Sener BC, et al. Lymphangioma treatment with Nd-YAG laser. Turk J Pediatr 1995;37(3):253-6.

[19] Pereira JC, Marques SDA. Lymphangioma of the mouth mucosa. Ars Curandi Odontol 1979;6(3):38-40.

[20] Landing BH, Farber S. Tumours of the cardiovascular system. Atlas of Tumour Pathology. Sect. III Fasc. 7. Washington, DC: Armed Forces Institute of Pathology 1956.

[21] Matharu J, Patel V. Cryotherapy for the management of a lip lymphangioma-a case report and literature review. Oral Surg 2019;12(3):230-7.

[22] Orford J, Barker A, Thonell S, et al. Bleomycin therapy for cystic hygroma. J Paediatr Surg 1995;30(9):1282-7. 